\title{
Entrevista
}

\section{El audiovisual superheroico}

\author{
Elisa McCausland"
}

Universidad Complutense de Madrid, España

1.- En muchas ocasiones se ha acusado a las películas de superhéroes el hecho de ser un formato "enlatado", con escasas sorpresas a la hora de construir la narrativa y en la manera en que son filmadas. Incluso en una ocasión te has referido a su "mediocridad visual”. ¿En qué casos te parece posible un nuevo camino, detectar marcas propias del director de cine que vayan más allá del texto del cómic, innovando incluso sobre la técnica cinematográfica?

Las imágenes de lo superheroico en el cine suelen servir a propósitos narrativos y dramáticos. Pocas veces al efecto de debatir en su seno aspectos como lo apolíneo y lo dionisiaco, lo arquetípico, cuando en resumidas cuentas el superhéroe y la superheroína son trasuntos contemporáneos de la mitología y, por ser más exacta, de la representación de esa mitología. Mientras que en el ámbito del cómic hay numerosos autores (Jack Kirby, Neal Adams, Frank Quitely, Frank Miller) que han entendido esto de sobra, la mayor parte del cine de este género ha abogado, y continúa abogando, por lo funcional. Hay excepciones, pero en líneas generales el panorama expresivo es pobre, lo que redunda en una domesticación de la figura del superhéroe, en el menoscabo de sus aspectos sublimes y terribles. Se pueden rescatar momentos de exploración en algunos fragmentos de Darkman (Sam Raimi, 1990), la trilogía de lo superheroico de M. Night Shyamalan -El Protegido(2000), Split (2016) y Glass (2019) -, las películas de Zack Snyder y Wonder Woman (Jenkins, 2017). Muy poco si tenemos en cuenta las increíbles posibilidades que ofrecen a día de hoy los efectos especiales que en la práctica solo están sirviendo para apuntalar un neoclasicismo digital: actores disfrazados que hablan frente a cromas.
2.- ¿Cómo podemos entender la modalidad de "cine seriado" que proponen las películas de superhéroes? ¿Se trata de una mixtura entre el formato cinematográfico y las series?

Teniendo en cuenta que a la hora de responder a estas preguntas está a punto de ver la luz la plataforma de visionado en streaming de Disney, que tiene entre sus mayores alicientes la presencia de superhéroes que hasta ahora habíamos visto en pantalla grande, no cuesta llegar a la conclusión de que no hay ninguna diferencia para la compañía entre un medio y otro. La transición (puesto que la películas de Marvel-Disney han cerrado, por ahora, un ciclo) va a ser inapreciable. Algo que hace pensar en hasta qué punto las películas no han constituido en realidad sino capítulos lujosos de un universo menos cinemático que televisivo. Por tanto, como se apunta en la pregunta, existe una correlación muy estrecha entre la gran pantalla y la pequeña.

3.- ¿En qué casos te parece más evidente la relación del audiovisual del superhéroe con su marco social? Por ejemplo, en distintas ocasiones se ha hablado de los cambios en las narrativas post $11-\mathrm{S}$, o con las crisis económicas desplegadas a nivel mundial a partir de 2008 ...

Hasta hace unos años el éxito de los superhéroes podían interpretarse como un síntoma de un intento de la esfera pública y cultural por exorcizar crisis sucesivas: el 11-S y la Gran Recesión iniciada en 2008 (McCausland y Salgado, 2016; Salgado, 2016). En la actualidad son más bien reflejo de cómo el capitalismo global ha sobrevivido a dichas crisis: potenciando el poder de las marcas hasta hacer de ellas las auténticas narrativas de la ficción, y equiparando a ellas los argumentos del feminismo y la diversidad. Una com-

*reinohueco@gmail.com 
binación, por ahora, ganadora pues las emociones del público están alineadas con una política de consumo.

4.- ¿'Te parece que ha cambiado la narrativa de superhéroes a partir de la nueva ola feminista de los últimos años? ¿Han cambiado las representaciones sobre lo femenino y lo masculino?

Hilando con la respuesta anterior, las expresiones del capitalismo $-\mathrm{y}$ la que vivimos ahora mismo no es una excepción - están ligadas íntimamente a un sistema de valores que emana de unas estructuras que el feminismo cuestiona desde los tiempos de la Ilustración, es decir, no se puede abrazar el capitalismo, incluido el cultural, y afirmar al mismo tiempo con complacencia que se está a favor del feminismo. Hay una complejidad y unas tensiones que nos obligan a preguntarnos qué pretende el capital cuando presume de feminismo en sus expresiones culturales, y qué pretendemos abrazar nosotros mismos en realidad cuando adoptamos esos discursos. Lo interesante, en definitiva, es interpretar qué significan en última instancia esos cambios en las dinámicas feministas de las imágenes, ante todo cosméticos en mi opinión; al menos hasta el momento. Los momentos feministas, a veces tan solo planos que buscan la emoción de una parte de la audiencia, no pueden soslayar lo conformista del conjunto de estos productos en los que significativamente los (súper) hombres siguen sosteniendo el aparato de la ficción. Basta observar lo que sucede en la que ya es una de las películas más taquilleras de la historia del cine, Vengadores: Endgame (Russo y Russo, 2019), en la que la superheroína Viuda Negra, tras desempeñar en varias películas de Marvel el papel de sostén emocional y comodín sentimental de sus compañeros vengadores, muere en mitad de la película como necesario punto de inflexión dramático y apenas es recordada en las últimas escenas, que son una oda al señor Tony Stark, pilar carismático masculino de todo este universo.

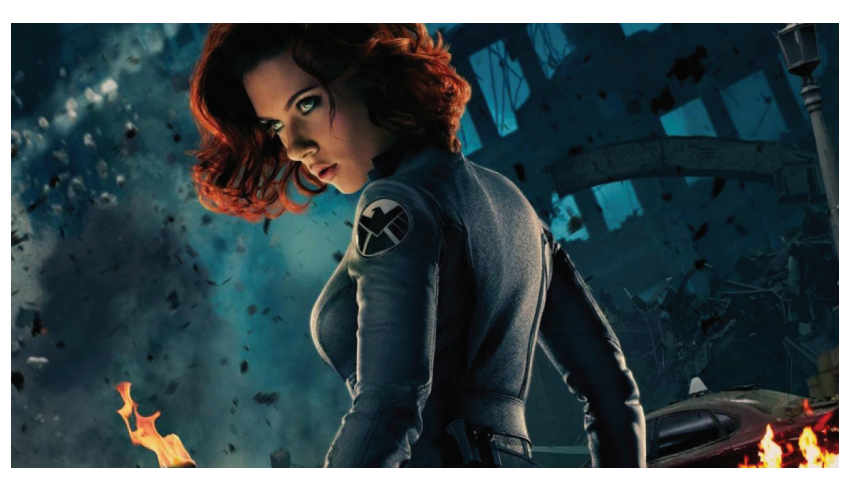

5.- ¿Qué interés puede tener el cine de superhéroes para la perspectiva feminista? ¿Cuáles son sus aportes y contradicciones?

Como ha ocurrido siempre en el cómic, el universo superheroico es un marco privilegiado para hablar sobre cómo se conforma, cómo se reparte el poder. Puesto que el poder, en la realidad, está en manos del heteropatriarcado, las fábulas de este tipo ofrecen un potencial inusitado para el feminismo: ¿Significa lo mismo que tengan superpoderes un hombre y una mujer? ¿La misión del superhéroe es equiparable a la de la superheroína? ¿Por qué las villanas, las antisistema, ejercen en tantas ocasiones de reflejo delator de las servidumbres sistémicas de las superheroínas? En los cómics tenemos ejemplos como la Wonder Woman del clan Marston y HG Peter (1941), la Promethea de Alan Moore (1999) y JH Williams o la Batwoman de Greg Rucka (2009), que han profundizado en estas cuestiones. En el audiovisual resulta obvio que la cosa ha dejado mucho que desear, lo que nos obliga a contentarnos con un simplemente esbozado en títulos como Wonder Woman y Capitana Marvel (Bodoen y Fleck, 2019). Es fuera de los cánones Marvel/DC donde se han producido las adaptaciones superheroicas más atrevidas como puede ser Kick Ass 2: Con un par (Wadlow, 2013) o la muy reciente $X$-Men: Fénix Oscura, del director británico Simon Kinberg (2019), que arriesga bastante más a la hora de innovar en lo que respecta al arquetipo de la superheroína que Patty Jenkins en Wonder Woman o Anna Boden y Ryan Fleck en Capitana Marvel.

6.- ¿Piensas que hay una mutación en los personajes de superhéroes en lo audiovisual, desde el boom de principios del siglo XXI hasta ahora, o más bien mantienen una caracterología básica explorando distintas formas narrativas?

El estreno en 2008 de Iron Man (Favreau) y El Caballero Oscuro (Nolan), cara y cruz de una manera de entender lo superheroico, permitía tener la esperanza de una auténtica Edad de Oro en lo que respecta a aquello que se apunta en la pregunta, una serie de mutaciones y exploraciones del arquetipo que fueran enriquecedoras para la audiencia (McCausland, 2016). 


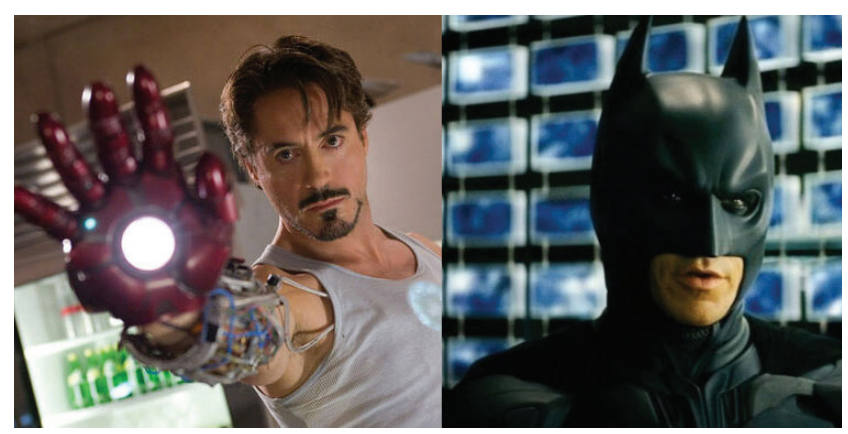

Diez años después, sin embargo, el superhéroe y la superheroína se han visto reducidos a la mínima expresión, presas de una pinza que conforman la desustanciación de los discursos más críticos y la sumisión a un público infantil e infantilizado.

7.- ¿Existen superhéroes "correctos" o "incorrectos"? ¿En qué radica la "compostura" o la "incorrección" de estos personajes?

La incorrección es, o debería ser, consustancial al superhéroe, pues al fin y al cabo sus poderes excepcionales le plantean, y plantean a la ficción, dilemas apasionantes. El superhéroe se halla fuera del marco social que la convención le obliga a defender: Es un superhombre en el aspecto nietzscheano de la palabra. Esto se ve aún más marcado en el caso de la superheroína. ¿Por qué debería defender las bondades de un sistema que ejerce un poder represivo sobre las mujeres? Como he comentado antes, quizás su misión heroica habría de consistir en la destrucción de ese sistema. Por tanto, mantener la compostura es algo contradictorio cuando hablamos de lo superheroico. La corrección es equiparable a la medianía, y la ética de los superhéroes y los supervillanos, de las superheroínas y las supervillanas, representa justamente la negativa a aceptar aquello que entendemos por normalidad.

8.- ¿Cuáles son, desde tu punto de vista, las características de los superhéroes y superheroínas que generan mayor identificación con el público actual? ¿Y de los villanos y villanas?

En línea con la respuesta anterior, una de las películas de superhéroes más políticas del año es Glass, en la que M. Night Shyamalan se atreve a cuestionar un cierto orden imperante que nos niega la posibilidad de profundizar en nuestros potenciales en aras de la tranquilidad psicológica.

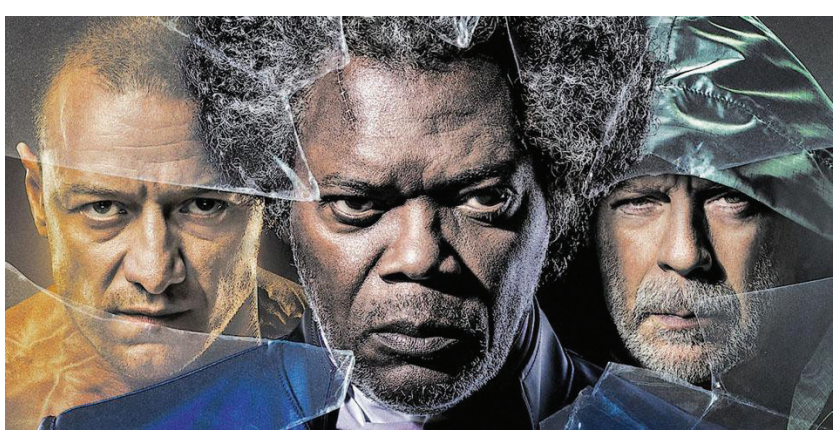

Cabría preguntarse qué busca el público actual en el audiovisual superheroico: si una identificación que pasa por la reducción del superhéroe y de la superheroína a su altura, o por una mirada al abismo que le haga replantearse su complacencia con el mundo que le rodea (Berlatsky, 2016). La respuesta a este dilema ofrece un balance muy revelador en torno a las sintonías del público con héroes y villanos (Claverie, 2016). No parece casual que, al menos en España, exista una auténtica fascinación con el villano de las dos últimas entregas de Los Vengadores, Thanos, cuya filosofía sobre la existencia, por radical que parezca, está en el fondo mucho más elaborada que las motivaciones inmaduras de sus antagonistas, que actúan como superhéroes por inercia tal y como exigen las líneas maestras del universo Marvel/Disney.

9.- ¿Qué piensas acerca de la representación explícita de la violencia en el cine de superhéroes?

Partiendo de la base de que la violencia en el arte es un recurso expresivo y alegórico más, su uso es tan legítimo como el de cualquier otro útil del creador. Es imposible entender Miracleman (Anglo, 1954), un cómic clave para comprender los dilemas éticos del superhéroe a los que ya me he referido, sin la violencia que destilan en muchos momentos sus viñetas. Lo mismo se puede decir en pantalla de momentos escatológicos como los que provoca HitGirl en Kick Ass 2: Con un par o la crueldad que emplea una Fénix Oscura en la última entrega de la saga $X$-Men contra los patriarcas del ecosistema mutante. Por tanto, no sería disparatado pensar que la falta de fricción en las imágenes pudiera ser síntoma de cierta intolerancia a discursos de una mínima complejidad artística, política. 


\section{Referencias}

Anglo, M. (1954). Miracleman. Estados Unidos: L. Miller \& Son.

Berlatsky, N. (24 de mayo de 2016). Superheroes Aren't Modern Myths (They’re Melodramas) [Mensaje en un blog]. Recuperado de: https://randomnerds.com/superheroes-arent-modern-myths-theyre-melodramas/

Biensstock, M., Shyamalan, M.N., Blum, J. (productores) y Shyamalan, M.N. (director). (2016). Split [cinta cinematográfica]. Estados Unidos: Blinding Edge Pictures, Blumhouse Productions.

Blum, J., Shyamalan, M.N. (productores) y Shyamalan, M.N. (director). (2019). Glass [cinta cinematográfica]. Estados Unidos: Blinding Edge Pictures, Blumhouse Productions, Universal Studios, Walt Disney Studios Motion Pictures, Touchstone Pictures.

Claverie, E. (2016). The Hollywood superhero as brand manager: an allegory of intellectual property [Mensaje en un blog]. Recuperado de: https://www.ejumpcut.org/archive/jc57.2016/-ClaverieSuperheroIP/index.html

Feige, K., Arad, A. (productores) y Favreau, J. (director). (2008). Ironman[cinta cinematográfica]. Estados Unidos: Marvel Studios.

Feige, K. (productor) y Boden, A. y Fleck, R. (directores). (2019). Capitana Marvel [cinta cinematográfica]. Estados Unidos: Marvel Studios.

Feige, K. (productor) y Russo, A. y Russo, J. (directores). (2019). Avengers: Endgame [cinta cinematográfica]. Estados Unidos: Marvel Studios.

Johns, G., Snyder, Z., Snyder, D., Berg, J. (productores) y Jenkins, P. (director). (2017). Wonder Woman [cinta cinematográfica]. Estados Unidos: DC films.

Marston, W.M. y Peter, H.G. (1941). Wonder Woman (All Star Comics \#8). Nueva York: DC Comics.

McCausland, E. (14 de mayo de 2016). El superhéroe en el diván. Diagonal. Recuperado de: https://www.diagonalperiodico.net/ culturas/30334-capitan-america-civil-war-superheroe-divan.html

McCausland, E.; Salgado, D. (2016). Debate en torno a las formas del audiovisual contemporáneo de superhéroes. CuCo, Cuadernos de cómic, 6, 93-118.

McCausland, E.; Salgado, D. (Productores). (10 de mayo de 2018). Superhéroes, Superproductos [Audio en podcast]. Recuperado de: https://www.consonni.org/es/superheroes-superproductos-1x01. Editorial Consonni

Moore, A. (1999). Promethea. Estados Unidos: America's Best Comics.

Pitt, B., Vaughn, M., Bohling, A., Pack, T., Reid, D. (productores) y Wadlow, J. (director). (2013). Kick Ass 2 [cinta cinematográfica]. Reino Unido: Marv Films, Plan B Entertaiment.

Rucka, G. (2009). Batwoman. Estados Unidos: DC Comics.

Salgado, D. (2016). El nuevo cine de superhéroes [Mensaje en un blog]. Recuperado de: https://www.cineparaleer.com/punto-de-vis$\mathrm{ta} /$ item/1889-el-nuevo-cine-de-superheroes

Shuler Donner, L.,Kinberg, S., Singer, B. (productores) y Kinberg, S. (director). (2019). Dark Phoenix. [cinta cinematográfica]. Estados Unidos: Marvel Entartainment, 20th Century Fox, Walt Disney.

Shyamalan, M.N., Mendel, B., Mendel, S. (productores) y Shyamalan, M.N. (director). (2000). Unbreakable [cinta cinematográfica]. Estados Unidos: Touchstone Pictures, Blindin019g Edge Pictures, Barry Mendel Productions, Limited Edition Productions Inc.

Tapern, R. (productor) y Raimi, S. (director). (1990). Darkman [cinta cinematográfica]. Estados Unidos: Renaissance Pictures.

Thomas, E., Roven, C., Nolan, C. (productores) y Nolan, C. (director). (2008). The Dark Knight [cinta cinematográfica]. Estados Unidos: Legendary Pictures, Syncopy Films. 